\title{
APRENDIZAGEM ATIVA PAUTADA NA DRAMATIZAÇÃO: MOE (MANTLE OF THE EXPERT)
}

\author{
Benta Cristina Souza \\ Universidade do Vale do Itajaí \\ Navegantes, SC, Brasil \\ bentac@gmail.com
}

\author{
Priscila Flores da Luz \\ Univerdade do Vale do Itajaí \\ Penha, SC, Brasil \\ priflores.biologa@gmail.com
}

\author{
Rodrigo Levi Rufca \\ Universidade do Vale do Itajaí \\ Itajaí, SC, Brasil \\ r.levi@univali.br
}

\begin{abstract}
Teaching is a challenging and complex process, using an effective, creative and playful teaching practice is necessary in schools. The aim of this study is to characterize the pedagogical approach MoE (Mantle of the Expert) and its aspects for the development of learning. This approach is an active methodology that converges to the new challenges of teaching, as the $\mathrm{MoE}$ is based on the experience, dramatization, reflection and problem solving, in which this method has three central elements: the team of specialists, the client and their task . In this imaginary context, students simulate and immerse themselves in their mission as a specialist in a certain area and need to deliver a final product to their client. This article will take a theoretical approach to $\mathrm{MoE}$, in addition to establishing correlations both with BNCC and with education theorists, from classics to contemporaries, for learning purposes.
\end{abstract}

\section{KEYWORDS}

MoE. Dramatização. Aprendizagem.

\section{Introdução}

Diante de anos de vivência de um currículo pouco flexível, ensino por repetição, uma dinâmica escolar centrada na figura do professor como transmissor e do aluno como receptor passivo do conhecimento, quebrar estes paradigmas e ensinar no século XXI é um imenso desafio [14]. No entanto, para [4], lecionar determinados conteúdos que não estão presentes no cotidiano do discente é ainda mais difícil. Além disso, muitos alunos apresentam desinteresse e faltam recursos escolares em amplo aspecto, portanto é urgente desenvolver aulas diferenciadas para melhorar o panorama educacional atual.

Despertar o interesse do aluno, trazer o conteúdo para a realidade e promover um aprendizado ativo e efetivo são desafios para o processo de ensino e aprendizagem.

Frente a este cenário, há uma abordagem pedagógica, intitulada MoE - "Mantle of the Expert", que cria realidades simuladas para desenvolver o currículo de forma adaptável, utilizando drama, experimentação, pesquisa e tecnologia para construir saberes, ensinar de forma lúdica e envolver os alunos no processo de aprendizagem [1]
No MoE os professores trabalham em colaboração com seus alunos para gerar cenários fictícios que são usados para estudar os conteúdos curriculares e desenvolver conhecimentos, habilidades e compreensão em áreas abrangentes.

Se o peso de ensinar for compartilhado entre professores e alunos na sala de aula, eles podem transformar de maneira positiva o ambiente escolar, tendo sempre como objetivo principal a aprendizagem [1]

Nessa abordagem, há convenções dramáticas advindas do teatro, que são inseridas para dar "tensão" e desenvolver o contexto ficcional. O que é muito importante, pois é nesse ponto que o aluno é atraído para a história. O objetivo é tornar o conhecimento cativante e colocar a turma no centro do processo de aprendizagem. O MoE não é conduzido por crianças, no sentido que os alunos tomam todas as decisões, pelo contrário, é algo colaborativo, em que professor e aluno trabalham juntos para construir o contexto e gerar atividades intencionais para a aprendizagem [16].

Conforme [11]o MoE orienta-se para a resolução de problemas, no qual os alunos assumem responsabilidades, têm poder de influência e de tomada de decisões inerentes ao grupo. Isso gera a oportunidade de aprender ativamente, de atuar no mundo, opinando, criticando e utilizando a imaginação, criatividade e proatividade para solucionar as situações que aparecem através do trabalho em equipe.

A questão norteadora da pesquisa, baseou-se em como mostrar que o MoE pode contribuir ativamente para o ensinoaprendizagem, tal problema de pesquisa teve respostas nas ideias de teóricos educacionais, correlações com a BNCC e referenciais teóricos sobre desenvolvimento da aprendizagem.

\section{Fundamentação Teórica}

Durante a construção do saber, é fundamental motivar os alunos para que eles tenham uma aprendizagem efetiva, um discente que quer aprender, faz toda a diferença na aquisição de conhecimento. Na contramão, a escola por vezes é enfadonha e cansativa, e, para que haja mudança o professor é fundamental, visto que com um planejamento adequado, que inclua variações e uma prática lúdica 
pode provocar uma transformação na forma de participação e no interesse do aluno [9].

Segundo [7], a motivação é essencial para aprender, porém a intervenção para motivação ocupa um lugar subsidiário na prática educativa. É espontânea no ser humano a vontade de trocar e de progredir, portanto o papel da intervenção educativa é alimentá-la. Para isso, o aluno deve ser agente ativo de sua aprendizagem.

$\mathrm{O} \mathrm{MoE}$ (Mantle of the Expert) apresenta-se como uma metodologia motivadora, pois o aluno vive o conhecimento como sujeito ativo, diante de seu próprio aprendizado. Nesse sentido, de acordo com [16] a abordagem alia elementos como dramatização, problematização e pensamento crítico para criar uma condição de estímulos da imaginação para realidade, a qual foi pensada e idealizada pela professora de teatro e educadora inglesa Dorothy Heathcote. Ela desenvolveu essa técnica durante sua vida docente para alunos em Newcastle (Inglaterra).

De acordo com [1], Dorothy iniciou o uso do MoE por volta de 1970. Seu propósito era tornar as técnicas dramáticas acessíveis aos professores, independente da área de atuação e experiência pedagógica. Assim, almejava encontrar formas de abrir portas para o conhecimento das crianças, auxiliando-as a estabelecer vínculos com a comunidade e a assumir responsabilidade pelo próprio aprendizado. Desta forma:

Seus métodos nunca foram criar salas de aula onde as crianças estão no comando, nem simulações onde, uma vez que os participantes entram no contexto, ficam até o fim. Ainda menos, uma grande mentira em que as crianças são levadas a acreditar no que está acontecendo. Em vez disso, como a peça imaginária, sua maneira de trabalhar era criar contextos dramáticos onde os envolvidos entendiam que estavam em uma ficção e podiam parar e iniciar a ação sempre que quisessem [16]

Segundo [16], essa abordagem permite uma vivência efetiva, com isso não ficou restrita somente ao espaço escolar, sendo aplicada em treinamentos de grandes empresas como Volkswagen e outras. Define-se MoE como:

Uso de drama e investigação para criar contextos imaginários para a aprendizagem. Os professores trabalham em colaboração com seus alunos para gerar cenários fictícios que são usados para estudar os currículos, habilidades e compreensão em áreas abrangentes. O objetivo é tornar o estudo curricular atraente e significativo, e colocar a comunidade da sala de aula no centro do processo de aprendizagem [16]

O MoE é uma opção para inovar o currículo, o qual atualmente é pouco flexibilizado. Essa técnica possibilita ajustes no programa curricular, no sentido interdisciplinar, determina-se um tema central e com o envolvimento dos alunos se amplia, fazendo do aluno o construtor do próprio conhecimento e fomentando nele a prática da pesquisa e a criatividade. Através da vivência do currículo pela dramatização e imersão, com o MoE, temas desconexos, de difícil entendimento e distantes da realidade dos alunos, tornam-se situações possíveis de se vivenciar, pois nessa abordagem os educandos fazem integralmente parte da história [11].

De acordo com [16] a abordagem MoE tem elementos primordiais para que sua aplicação seja exitosa, que são:

1- Elementos da Fundação (Contexto ficcional, narrativa e questionamentos);

2- Elementos Centrais (Time de especialistas, cliente e a tarefa ou missão);

3- Elementos Dramáticos (Diferentes pontos de vista, tensão e convenções dramáticas).

Conforme Boschi (2019), o MoE faz o uso de técnicas teatrais para se desenvolver, na qual acontecem algumas encenações nas quais os alunos são (ou sentem-se como se fossem) especialistas em algo, são efetivamente pessoas vivenciando a situação proposta e o professor direciona a situação garantindo que surja ao longo da história novos desafios.

Dorothy Heathcote apresenta convenções dramáticas que devem fazer parte do MoE, tais elementos são indispensáveis na imersão do aluno ao conteúdo, tais quais: um retrato, vestimenta ou objetos que representem algo, um modelo em tamanho real, uma carta ou documento, vozes, músicas, códigos enigmáticos etc. que atraiam a atenção e motivem um contínuo envolvimento [11].

O MoE se caracteriza como uma metodologia ativa de aprendizagem, pois consiste na didática centrada no aluno, expressando forte caráter colaborativo, reflexivo e participativo, tendo o docente como mediador e participante. Essa técnica possibilita alcançar experiências significativas e o objetivo de ensinar: o aprendizado efetivo [15]

A dramatização utilizada no MoE é um recurso que admite a troca de papéis e permite que o aluno "atue" os anseios presentes em seu papel de especialista. Sua finalidade é que com poucos recursos, de maneira espontânea e criativa, proporcione a experimentação e a reflexão dos pontos de vista de outras pessoas, ao interpretar um conteúdo, por exemplo, se a proposta de aula fosse sobre a guerra haveria a perspectiva do governante, do soldado e da família dele, consequentemente isso despertaria diversos olhares e posicionamentos críticos e empáticos [16].

As sessões de MOE podem durar apenas uma aula ou mais de acordo com o planejado e de acordo com a demanda da turma. Pode ser criada uma empresa onde os alunos fiquem várias aulas trabalhando nela e desenvolvendo os conhecimentos antes propostos pelo professor durante a elaboração. Outro aspecto importante do MOE é que não é necessário o uso de muitos materiais porque os alunos estarão usando a imaginação então se, por exemplo, uma das tarefas for varrer o chão não é necessário que os alunos possuem vassouras eles irão usar da criatividade [4].

O ensino por imersão com dramatização e resolução de problemas, valoriza o desenvolvimento das competências gerais (Tabela 1) conforme preconiza a Base Nacional Comum Curricular (BNCC, 2017). 


\begin{tabular}{|c|l|}
\hline Competência & \multicolumn{1}{|c|}{ Objetivo } \\
\hline Conhecimento & $\begin{array}{l}\text { Valorizar e utilizar os conhecimentos sobre o mundo fisico, } \\
\text { social, cultural e digital. }\end{array}$ \\
\hline $\begin{array}{c}\text { Pensamento Científico, Crítico e } \\
\text { Criativo }\end{array}$ & $\begin{array}{l}\text { Exercitar a curiosidade intelectual e utilizar as ciências com } \\
\text { criticidade e criatividade }\end{array}$ \\
\hline Repertório Cultural & Valorizar as diversas manifestações artísticas e culturais. \\
\hline Comunicação & Utilizar diferentes linguagens. \\
\hline Cultura Digital & $\begin{array}{l}\text { Compreender, utilizar e criar tecnologias digitais de forma } \\
\text { critica, significativa e ética. }\end{array}$ \\
\hline Trabalho e Projeto de Vida & Valorizar e apropriar-se de conhecimentos e experiências. \\
\hline Argumentação & $\begin{array}{l}\text { Argumentar com base em fatos, dados e informaçães } \\
\text { confiáveis. }\end{array}$ \\
\hline Autoconhecimento e Autocuidado & $\begin{array}{l}\text { Conhecer-se, compreender-se na diversidade humana e } \\
\text { apreciar-se. }\end{array}$ \\
\hline Empatia e Cooperação & $\begin{array}{l}\text { Exercitar a empatia, o diálogo, a resolução de conflitos e a } \\
\text { cooperação. }\end{array}$ \\
\hline Responsabilidade e Cidadania & $\begin{array}{l}\text { Agir pessoal e coletivamente com autonomia, } \\
\text { responsabilidade, flexibilidade, resiliência e determinação. }\end{array}$ \\
\hline
\end{tabular}

Tabela 1 Competências Gerais da BNCC. Fonte: Elaborada a partir da BNCC (2017).

A BNCC é um documento normativo que define as aprendizagens essenciais que todos os alunos devem desenvolver nas etapas e modalidades da Educação Básica, para assegurar os direitos de aprendizagem e desenvolvimento, orienta-se por princípios éticos, políticos e estéticos que visam à formação humana integral e à construção de uma sociedade justa, democrática e inclusiva [3].

O MoE possui aspectos em comum com a metodologia ativa denominada aprendizagem baseada em problemas (PBL) porém, com peculiaridades e dramatização. De acordo com [8] a PBL é centrada no estudante, autodirigida e individualizada, se projeta e aprimora para a resolução do problema. Os professores atuam como facilitadores e colaboradores. Nela, os alunos encontram a informação, analisam, resumem os dados e solucionam o problema. Isso potencializa qualidades como autonomia e autoconfiança. Enfatiza-se que a dinâmica de questionar e raciocinar sobre uma determinada situação contribui no desenvolvimento da forma de pensar.

Segundo os Parâmetros Curriculares Nacionais (PCNs) do componente curricular Matemática [2], a resolução de problemas possibilita aos alunos mobilizar conhecimentos e desenvolver a capacidade de gerenciar as informações que estão a seu alcance. Assim, os alunos têm chances de amplificar as possibilidades de saberes acerca de conceitos e problemas.

Para cumprir seu papel de ensino efetivo e ativo, o MoE requer do professor um minucioso planejamento, exige um grande comprometimento tanto do educador quanto dos alunos, já que utiliza a dramatização e questionamentos para gerar aprendizagem, essa é uma abordagem pedagógica trabalhosa, pois visa o desenvolvimento efetivo e enriquecedor da interação entre conteúdo e prática para que potencialize a reflexão sobre o que se faz, como se faz, por que se faz, quais os resultados do que se fez, os objetivos pelos quais se almeja os resultados e como aperfeiçoá-lo [11].
Ao iniciar a prática do MoE é importante ter uma sondagem dos alunos e suas preferências, para conseguir promover um início impactante, que chame a atenção dos alunos. Um pretexto adequado pode despertar interesse, espontaneidade, criatividade, participação e um potencial reflexivo que é essencial a essa prática. O professor também precisa ter muito claro o que é preciso realmente ensinar, para contextualizar e conduzir o processo de aprendizagem com moderação à prática (parcimônia) e generosidade de opções (prodigalidade). Nessa perspectiva, é preciso ter uma bússola do professor para nortear o trabalho pedagógico [11].

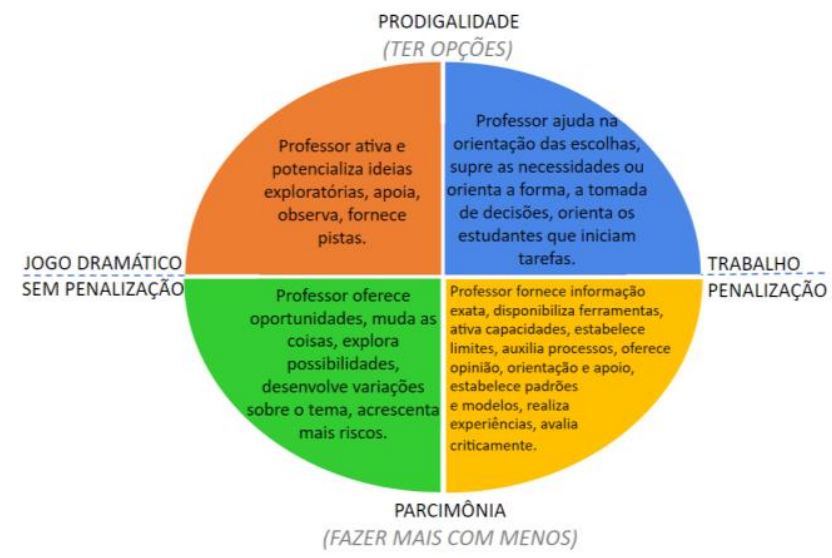

Figure 1 Bússola do professor de Dorothy Heathcote. Fonte: elaborada a partir de NOGUEIRA et al. 2017.

Ressalta-se que o método MoE não é simplesmente uma representação ou um teatro, pois os alunos não decoram textos: eles vivenciam a partir do ponto específico do conteúdo a ser dramatizado desenvolvendo, assim, o próprio conhecimento [4]. Dessa forma, a simulação permite que as competências a serem desenvolvidas sejam efetivamente praticadas [15]

Há um passo a passo específico do MoE e [11]cita suas etapas, bem como [16] exemplifica a abordagem:

1- Planejamento (considerar nesse plano o objetivo principal do conteúdo curricular, o que se pretende ensinar de forma específica, os aspectos de interesse do aluno, a formulação de conflitos e linhas de questionamentos a serem respondidos e os recursos disponíveis e os necessários). Por exemplo, imagine que uma turma se interesse por aprender mais sobre castelos, cavaleiros e contos míticos, então o professor deve explicar aos seus alunos o que será ensinado, delimitando alguns aspectos que sejam de essencial apropriação; 


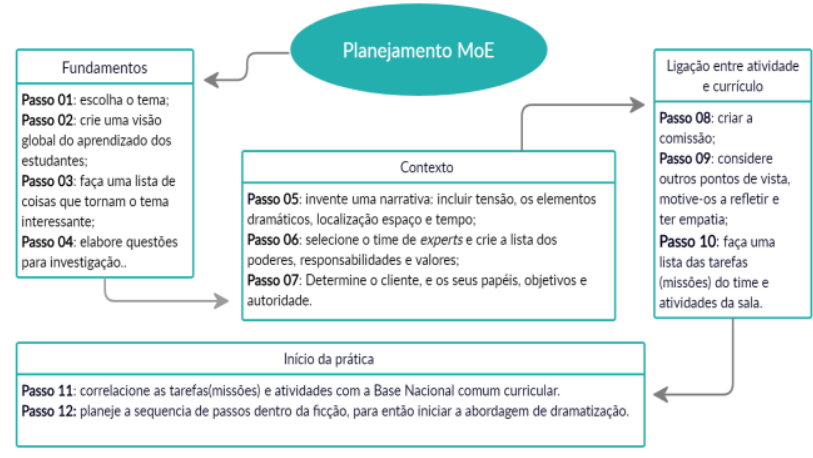

Figure 2 Modelo de planejamento MoE. Fonte: elaborada a partir de TAYLOR (2016).

2- Definição quanto ao contexto do especialista (nessa etapa se cria um roteiro, observando os grupos de alunos que serão especialistas, os clientes, outros papéis e se define a encomenda, tarefa ou a missão a ser cumprida). Esta etapa pode ser exemplificada da seguinte forma: em um contexto imaginário, as crianças formam uma equipe de restauração, encomendada pela empresa British Heritage para restaurar um antigo castelo em ruínas e abri-lo ao público. A comissão exige que a equipe pesquise a história do castelo, descubra histórias de seu passado e conscientize as pessoas que visitam o local quais cuidados e informações necessárias.

3- Delineamento das atividades, criação de um "contrato" moral, ético e de responsabilidade junto aos alunos para realização da atividade e atribuição a cada participante de sua missão, bem como estipular de que maneira tais atividades se articulam com o conteúdo curricular que se pretende desenvolver (elaborar as encomendas/missões que permitam exploração e pesquisa visando olhar crítico e diversos pontos de vista sobre o tema). Nesta etapa encontramos os três pilares da abordagem, que para [17] e [1] são: o time de especialista ou experts, a tarefa e os clientes. Por essa perspectiva, podemos detalhar da seguinte forma:

a. Os alunos são os especialistas e trabalham para um cliente que executam uma missão de forma fictícia como se fossem uma equipe de peritos no assunto com poderes e responsabilidades inerentes de seus cargos;

b. A tarefa, encomenda ou missão é o que precisa ser realizado em conjunto pela equipe de forma colaborativa para criar o produto ou resolver um problema. Como há uma demanda a ser entregue, já que o cliente está solicitando uma tarefa ou serviço, o aluno fará o uso de tudo que dispõe e que pode servir à concretização da solicitação: computador, impressora, cartazes, canetas, tintas, câmeras, gravadores, entre outros;

c. O cliente cobra, define os padrões, fornece as informações sobre o que será solucionado e encarrega a equipe de executar as missões objetivando a resolução, o que cria oportunidade para os alunos pesquisarem de forma ampla, ativa e responsável.

Para [11] no planejamento do $\mathrm{MoE}$, o professor insere progressivamente elementos desafiadores para que o time de especialistas (alunos) sejam atores protagonistas na construção do conhecimento, pois estão cercados de oportunidades para explorar o currículo, ou aquilo que desejam aprender, assim a tarefa é exploração real do que ocorreu na ficção.

O interesse e o comprometimento das crianças com o trabalho podem aumentar à medida que seus conhecimentos e entendimentos se desenvolvem. Nesse exemplo de prática sobre a história dos castelos os alunos leem livros: histórias, mitologia, lendas e contos de fadas. Podem ser elaborados diferentes tipos de textos, incluindo livros de informações, histórias, folhetos e artefatos históricos (cartas, decretos e notas secretas). É possível desenhar mapas, diagramas, pintar, produzir tapeçarias, criar filmes e animações com os alunos roteiristas, projetistas, atores, editores e produtores.

4- Preparação para a intervenção (aplicação da sequência didática planejada para o conteúdo no contexto ficcional, durante o desdobramento envolve: questões orientadoras (para ação, motivação, investimento, postura, modelos ou valores), níveis de exigência e o produto/evento/resultado final. Tudo que foi construído pode culminar em um vídeo, uma peça teatral, um produto produzido como uma maquete e exibido para toda comunidade escolar ao final do semestre ou simplesmente servir para aprender e trazer algo de concreto ao vivenciar um conteúdo.

Cabe considerar a afirmação [11] na qual determina que cada aluno pode ter um nível de envolvimento ou papel no drama: participante, observador, guia, agente, autoridade, investigador, artista, entre outros. No entanto, independente do papel, é preciso destacar o mérito e a responsabilidade de cada integrante para o resultado final, que é compartilhar um conhecimento pela imersão no intuito de aprender. Pode-se ainda ocorrer diversas maneiras de representação dramática dentro do MoE como: ativa (ação); icônica (visual) e simbólica (palavras, linguagem e abstração).

No contexto desenvolvido pelo MoE, manter a concentração do aluno é fundamental. Para isso, é importante estabelecer níveis de envolvimento para agregar todos à prática. Assim deve haver: investimento, motivação, interesse, atenção e atração. Utiliza-se muito do intuitivo e questões intencionais como: aquilo que já conhecem, o que gostariam de saber, o que não fazem ideia e além destes questionamentos propor alternativas e criar estratégias de pesquisa para embasar a dramatização [11].

$\mathrm{O} \mathrm{MoE}$ pode reunir muitas áreas de estudo curricular, em uma abordagem flexível que pode ser usada de várias maneiras. Porém, o único recurso que todos compartilham é o modo como a aprendizagem curricular é contextualizada dentro de um cenário imaginário, colocando os alunos como pessoas com status e responsabilidade, e é isso que dá propósito e significado ao aprendizado.

Corroborando com [12]a aprendizagem é mais eficiente quando envolve experimentação, criatividade, colaboração e situações práticas. $\mathrm{Na}$ abordagem $\mathrm{MoE}$ ocorre o desenvolvimento de processos criativos por meio da dramatização de uma proposta. Nessa proposta, há ainda "os quatro Ps" de uma técnica intitulada Aprendizagem Criativa, a qual é descrita por [13]: projeto, paixão, parcerias e pensar brincando. No processo de ensino e 
aprendizagem, os quatro Ps proporcionam planejamento e possibilidades de criar, de testar situações cotidianas para atuar de forma ativa perante os problemas sociais e as temáticas envolvidas na proposta.

A Aprendizagem Criativa no contexto aplicado ao MoE oportuniza o desenvolvimento de competências gerais da BNCC. A principal é a própria criatividade, quando imergimos os estudantes na criação de um produto ou solução, estimula-se que o aluno seja protagonista, além disso, desenvolve o pensamento crítico, pois é necessário questionar e no caso do MoE dramatiza uma realidade simulada.

De acordo com [1]um aspecto relevante é que durante a pesquisa e desenvolvimento da tarefa a ser proposta no MoE, o professor é um guia que realiza questionamentos dentro de um personagem, normalmente é o cliente, visando desafiar ou apoiar os alunos. O professor pode até pausar a "cena" e fornecer orientações fora do personagem visando conduzir de forma direcionada ao objetivo curricular, para imersão dos alunos que estão na trama de aprendizado.

Através do imaginário e ambientação para imergir o aluno no tema, o MoE se desenvolve. Assim, inicia-se dentro da situação a ser deliberada (coerentemente com planejamento da tarefa), para que os discentes o solucionem, porém, ao longo de todo processo de completar a missão, outras situações podem ser inseridas, desafiando os alunos a aprenderem ainda mais [1]).

Para Piaget (1949), uma prática de vivência constitui reflexos positivos, pois um aluno que experimenta, cria conexões amplas com aprendizagem.

Não se aprende a experimentar simplesmente vendo o professor experimentar, ou dedicando-se a exercícios já previamente organizados: só se aprende a experimentar, tateando, por si mesmo, trabalhando ativamente, ou seja, em liberdade e dispondo de todo o tempo necessário [10].

Com o intuito de gerar veracidade, no decorrer do MoE é preestabelecido pelo professor o agente de problemática e o docente também pode ser o cliente. Durante a abordagem, os grupos podem ser divididos em departamentos, por exemplo: departamento de trânsito, segurança, canal de televisão, entre outros. Nesse ínterim, os envolvidos têm autonomia para pesquisar, questionar, alterar alguns elementos, perguntar, tornando uma metodologia democrática e participativa [16].

Segundo [5], para que o discente possa aprender de uma forma relevante e compromissada com a liberdade é essencial autonomia, sendo esse elemento muito evidenciado no MoE.

Quando vivemos a autenticidade exigida pela prática de ensinar-aprender participamos de uma experiência total, diretiva, política, ideológica, gnosiológica, pedagógica, estética e ética, em que a boniteza deve achar-se de mãos dadas com a decência e com a seriedade [5].

Conforme [5] e [12] conquistar a atenção do aluno é desafiador. Para isso, é preciso que o professor se preocupe com os interesses e conhecimentos do educando, para que estabelecendo relações entre seu cotidiano e o conteúdo, perceba a importância do que está sendo ensinado. Nesse contexto, dramatizar faz o conteúdo tornar-se próximo ao "mundo real", de forma significativa, propiciando o despertar da curiosidade e participação na realização da missão a ser cumprida.

Com o MoE envolvendo os elementos das competências gerais da BNCC, a partir da resolução de problemas, da dramatização que permite ao aluno brincar e se expressar, com um caráter prático e participativo, proporciona ao aluno desenvolver conhecimento com o uso de diferentes linguagens, inclusive as digitais, para se expressar e compartilhar saberes. A compreensão e a utilização das tecnologias digitais como fonte de informação e possibilidade de comunicação, o trabalho colaborativo, o desenvolvimento da autonomia, da argumentação e da empatia como características estão incluídas nos planejamentos e nas aulas em todas as áreas do conhecimento [3].

Pode-se considerar o MoE como um caminho para avançar na aquisição de um conhecimento profundo, ao passo que os alunos assumem o "papel" de especialistas, pesquisam, problematizam e fazem descobertas, o que possibilita o desenvolvimento das competências gerais conforme preconiza a BNCC . O professor nessa abordagem não se foca apenas em transmitir informações, mas, em todo o processo de aprendizagem ele é o mediador como Vygotsky propõe em sua teoria:

Por outro lado, se a criança resolve o problema depois de fornecermos pistas ou mostrarmos como o problema pode ser solucionado, ou se o professor inicia a solução e a criança a completa, ou, ainda, se ela resolve o problema em colaboração com outras crianças - em resumo, se por pouco a criança não é capaz de resolver o problema sozinha - a solução não é vista como um indicativo de seu desenvolvimento mental. Esta "verdade" pertencia ao senso comum e era por ele reforçada. Por mais de uma década, pensadores sagazes nunca questionaram esse fato; nunca consideraram a noção de que aquilo que a criança consegue fazer com ajuda dos outros poderia ser, de alguma maneira, muito mais indicativo de seu desenvolvimento mental do que daquilo que consegue fazer sozinha [18]

Por meio de seus elementos, o MoE preconiza a aprendizagem dinâmica e ativa, durante esta abordagem pedagógica é possível encontrar aspectos da espiral da aprendizagem criativa que segundo [13] são: imaginar, criar, brincar, compartilhar, refletir e volta, ao imaginar em um movimento cíclico. Sendo assim, a espiral criativa pode ser vinculada ao MoE, e o aluno pode experienciar e resolver os vários desafios que ele pode encontrar na sala de aula e na sua vida.

Através de roteiros personalizados e grupais de aprendizagem, essa metodologia orienta o discente como um personagem dentro de uma proposta que está sendo dramatizada. Tal método de ensino-aprendizagem pode oportunizar inúmeros benefícios, como integração entre diferentes áreas do conhecimento, protagonismo do aluno, modelos curriculares flexíveis inter e transdisciplinares, tornando o processo de ensino motivador, atrativo e prazeroso, 
permitindo que o aluno participe ativamente de seu processo de aprendizado.

\section{Fundamentação Teórica}

O presente estudo consistiu em uma pesquisa documental e como tal, se propôs a analisar os aspectos sobre Mantle of the Expert (MoE) como uma metodologia ativa, suas correlações com a BNCC e com teorias de aprendizagem. A pesquisa documental ou revisão da literatura é um estudo crítico, minucioso e amplo das publicações correntes a respeito de um determinado objeto de conhecimento [17].

A pesquisa se desenvolveu a partir da análise e síntese da informação disponibilizada nos estudos publicados a respeito do MoE. Foram 18 (dezoito) fontes de informação que incluíram livros e periódicos, levantados através dos bancos de dados da SCIELO, CAPES, AMAZON, BNDigital, Google Scholar e biblioteca virtual da UNIVALI.

Vale salientar que no decorrer da nossa pesquisa entramos em contato, via reunião online, com Roberta Luchini Boschi, uma das autoras brasileiras de alguns dos artigos publicados, com o intuito de aprimorar nossos conhecimentos e ter a possibilidade de conversar sobre a experiência prática relacionada ao MoE.

Em conformidade com [6], o desenvolvimento deste trabalho cumpriu quatro etapas que propiciaram para nossas considerações finais: 1- Leitura exploratória; 2- Leitura seletiva; 3- Leitura crítica reflexiva e 4- Leitura analítica e interpretativa. Assim, por meio desta pesquisa, além de descrever o tema $\mathrm{MoE}$, apontamos impressões e correlações com o tema.

Este estudo não foi submetido ao Comitê de Ética da UNIVALI por se tratar de uma pesquisa documental sem envolvimento de seres humanos, no entanto, manteve-se o rigor ético que implica não transgredir a Resolução CNS n. 466/12. Além disso, houve o compromisso de citar os autores utilizados, respeitando-se a NBR 6023 (Referências). As informações coletadas na pesquisa foram utilizadas com finalidade científica.

\section{Fundamentação Teórica}

Desde que se formou como instituição, a escola, em muitos quesitos, manteve-se idêntica mesmo diante de décadas de transformações, tanto a sua infraestrutura quanto a prática pedagógica pouco se modificaram. E, em pleno século XXI, esse sistema parece estar em colapso, devido às mudanças rápidas que a sociedade tem passado, a instituição escolar demonstra não suprir a demanda desses alunos, que possuem acesso à informação de maneira instantânea e que tem demonstrado grande desinteresse pelas aulas. No entanto, uma das maneiras de reverter esse cenário é a utilização de metodologias mais atrativas durante o processo de docência, fazendo com que o aluno se torne centro do aprendizado como agente ativo na construção do conhecimento e estabeleça conexões do conteúdo com seu cotidiano.

Este artigo referenciou o Mantle of the Expert (MoE), criado por Dorothy Heathcote, um método que auxilia docentes na prática pedagógica de aprendizagem ativa e possibilita ao aluno conhecer o mundo não só pela razão, mas também pela dramatização, reflexão, criatividade, imersão do aluno no conhecimento e pela percepção do que nem sempre pode ser expresso por palavras.

A BNCC vem para mudar cenários e balizar a qualidade da educação no Brasil por estabelecer um nível de aprendizagem e desenvolvimento que é direito de todos os alunos, frisa-se, portanto, que com a base será exigido das escolas o uso de metodologias ativas que incentivem o protagonismo do aluno e o MoE é uma excelente opção nesse sentido.

O processo de construção do conhecimento a partir da abordagem dramática, agrega efetivamente na aprendizagem, pois além do caráter colaborativo e participativo, faz o aluno vivenciar o conteúdo, torná-lo concreto. Isso encontra amplo respaldo nos teóricos educacionais que apontam para a construção do conhecimento de forma ativa, bem como corrobora com as habilidades necessárias para o desenvolvimento de competências gerais da Base Nacional Comum Curricular.

As escolas precisam de práticas inovadoras e o uso de estratégias de ensino e aprendizagem ativas, propiciam a assimilação efetiva do conteúdo programático. Por ser uma prática diversificada e com múltiplas possibilidades de adaptação, proporciona $\mathrm{o}$ exercício da cidadania e do mundo do trabalho, pois desenvolve o potencial crítico-reflexivo do aluno, auxiliando-o a desenvolver habilidades como autonomia, protagonismo, atitudes e valores para resolver demandas de seu dia a dia [3]..

\section{Agradecimentos}

Começamos por agradecer a Deus que ao longo deste processo nos deu força para seguir, apesar de todas as adversidades... Não podemos deixar de apresentar toda a nossa gratidão a Univali Universidade do Vale do Itajaí por ser um espaço que privilegia o conhecimento e onde todas as ideias são bem recebidas e também gostaríamos de agradecer os professores, pelas correções e ensinamentos que foram muitos durante toda a nossa jornada nesta pós-graduação, mas em especial gostaríamos de agradecer aos professores Rodrigo Levi Rucaf e André Luís Alice Raabe, por toda a dedicação e orientação.

\section{REFERENCES}

[1] BOSCHI, Roberta Luchini. Mantle of the Expert (MOE) e o uso das tecnologias digitais na escola - uma experiência inglesa. Scias: Educação, Comunicação e tecnologia, Belo Horizonte, v. 1, n. 1, p. 24 38, ago. 2019. Disponível em: file:///C:/Users/UserPC/Downloads/3507-12677-1-PB\%20(1).pdf. Acesso em: 07 jun. 2020.

[2] BRASIL, Ministério da Educação e da Secretaria de Educação Fundamental. Parâmetros Curriculares Nacionais (Matemática). Brasília: A Secretaria, 1998.

[3] BRASIL. Ministério da Educação. Base Nacional Comum Curricular. MEC, 2017. Brasília, DF, 2017. Disponível em < http://portal.mec.gov.br/index.php?option $=$ com_docman\&view=downlo ad\&alias=79611 -anexo-texto-bncc-aprovado-em-15-12-17pdf\&category_slug=dezembro-2017-pdf\&Itemid=30192. Acesso em: 21 jun. 2020

[4] CALVO, Julia; SANTOS, Amanda; SOARES, Ana Clara; VELOZO, Matheus. O mundo feudal por meio do MOE: propostas de intervenção no ensino de história. 2015. 13 f. TCC (Graduação) - Curso de História, Pibid, Pontifícia Universidade Católica de Minas Gerais, Belo 
Horizonte, 2015. Cap. 1. Disponível em: file://C:/Users/UserPC/Downloads/12962-Texto\%20do\%20artigo-46475-1-10-

20160927.pdf. Acesso em: 07 jun. 2020.

[5] FREIRE, Paulo. PEDAGOGIA DA AUTONOMIA: saberes necessários à prática educativa. 25. ed. São Paulo: Paz e Terra, 1996.

[6] GIL, A. C. Métodos e técnicas de Pesquisa Social. $6^{\circ}$ ed. São Paulo: Atlas, 2010. Disponível em: https://ayanrafael.files.wordpress.com/2011/08/gil-a-c-mc3a9todos-etc3a9cnicas-de-pesquisa-social.pdf. Acesso em: 22 jun. 2020.

[7] HUERTAS, J. A. Motivación: querer aprender. Buenos Aires: Aique, 2001

[8] LOPES, R. M.; ALVES, N. G.; PIERINI, M. F.; SILVA FILHO, M. V. (Org.). Aprendizagem Baseada em Problemas: fundamentos para a aplicação no ensino médio e na formação de professores. 1ed. Rio de Janeiro: Publiki, v. 45, 2019. Disponível em: https:/educapes.capes.gov.br/bitstream/capes/432641/2/APRENDIZAG EM\%20BASEADA\%20EM\%20PROBLEMAS\%20-

$\% 20$ fundamentos $\% 20$ para $\% 20 \mathrm{a} \% 20$ sua $\% 20$ aplica $\% \mathrm{C} 3 \% \mathrm{~A} 7 \% \mathrm{C} 3 \% \mathrm{~A} 3$ o $\% 20$ no $\% 20$ Ensino $\% 20 \mathrm{M} \% \mathrm{C} 3 \%$ A 9 dio $\% 20 \mathrm{e} \% 20$ na $\% 2$ Forma $\%$ C $3 \% \mathrm{~A} 7$ $\% \mathrm{C} 3 \% \mathrm{~A} 3 \mathrm{o} \% 20 \mathrm{de} \% 20$ Professores.pdf. Acesso em: 05 jun. 2020.

[9] KNÜPPE, L. Motivação e desmotivação: desafio para as professoras do ensino fundamental. Educar em Revista, Curitiba, n. 27, p.277-290, 2006.

[10] MUNARI, Alberto. Jean Piaget. Tradução e organização de Daniele Saheb. Recife: Fundação Joaquim Nabuco, Editora Massangana, 2010.

[11] NOGUEIRA, Isabel Cláudia et al (org.). ENSINAR A APRENDER A DECIDIR, A PARTIR DO MANTLE OF THE EXPERT: (MoE). Rio de Janeiro: Escola Superior de Educação de Paula Frassinetti, 2017. 46 p. Disponível em: http://hdl.handle.net/20.500.11796/2517. Acesso em: 14 jun. 2020.

[12] PAPERT, Seymour. Logo: computadores e educação. J A Valente (Trad.). SP: Brasiliense, 1985.

[13] RESNICK, Mitchel. Jardim de infância para a vida toda : por uma aprendizagem criativa, mão na massa e relevante para todos [recurso eletrônico] / Mitchel Resnick ; tradução: Mariana Casetto Cruz, Lívia Rulli Sobral ; revisão técnica: Carolina Rodeghiero, Leo Burd.- Porto Alegre : Penso, 2020.

[14] SCHMIDT, Maria Auxiliadora; CAINELLI, Marlene. Ensinar História: pensamento e ação na sala de aula. São Paulo: Scipione, 2010.

[15] SENAC. DN. Metodologias ativas de aprendizagem. Rio de Janeiro, 2018. 43 p. (Coleção de documentos Técnicos do Modelo Pedagógico Senac, 7).

[16] TAYLOR, T. A beginner's Guide to Mantle of the Expert: a transformative approach to education. Norwich: Singular Publishing, 2016.

[17] TRENTINI, M.; PAIM, L. Pesquisa em Enfermagem. Uma modalidade convergente-assistencial. Rev. bras. enferm. vol.52 no.4 Brasília Oct./Dec. 1999 Disponível em: http://dx.doi.org/10.1590/S003471671999000400018. Acesso em: 19 jun. 2020.

[18] VYGOTSKY, L. S. A formação social da mente. São Paulo: Martins Fonte, 1991 . 